Article

\title{
Antibacterial Activity of Synthetic Cationic Iron Porphyrins
}

\author{
Artak Tovmasyan ${ }^{1}\left[\right.$, Ines Batinic-Haberle ${ }^{2}$ and Ludmil Benov ${ }^{3, *} \mathbb{C}$ \\ 1 Division of Neurobiology, Ivy Brain Tumor Center, Barrow Neurological Institute, Phoenix, AZ 85013, USA; \\ artak.tovmasyan@barrowneuro.org \\ 2 Department of Radiation Oncology, Duke University School of Medicine, Durham, NC 27710, USA; \\ ibatinic@duke.edu \\ 3 Department of Biochemistry, Faculty of Medicine, Kuwait University, Kuwait City 13110, Kuwait \\ * Correspondence: ludmil.benov@ku.edu.kw; Tel.: +(965)-2531-9489
}

Received: 24 August 2020; Accepted: 17 September 2020; Published: 10 October 2020

\begin{abstract}
Widespread antibiotic resistance demands new strategies for fighting infections. Porphyrin-based compounds were long ago introduced as photosensitizers for photodynamic therapy, but light-independent antimicrobial activity of such compounds has not been systematically explored. The results of this study demonstrate that synthetic cationic amphiphilic iron $N$-alkylpyridylporphyrins exert strong bactericidal action at concentrations as low as $5 \mu \mathrm{M}$. Iron porphyrin, FeTnHex-2-PyP, which is well tolerated by laboratory animals, efficiently killed Gram-negative and Gram-positive microorganisms. Its bactericidal activity was oxygen-independent and was controlled by the lipophilicity and accumulation of the compound in bacterial cells. Such behavior is in contrast with the anionic gallium protoporphyrin IX, whose efficacy depends on cellular heme uptake systems. Under aerobic conditions, however, the activity of FeTnHex-2-PyP was limited by its destruction due to redox-cycling. Neither iron released from the Fe-porphyrin nor other decomposition products were the cause of the bactericidal activity. FeTnHex-2-PyP was as efficient against antibiotic-sensitive E. coli and S. aureus as against their antibiotic-resistant counterparts. Our data demonstrate that development of amphiphilic, positively charged metalloporphyrins might be a promising approach in the introduction of new weapons against antibiotic-resistant strains.
\end{abstract}

Keywords: antibacterial; iron porphyrin; antibiotic resistance; bactericidal; cationic metalloporphyrin

\section{Introduction}

In a recent report, the $\mathrm{WHO}$ pointed to antimicrobial resistance as a global problem that poses a threat for the management of diseases caused by viruses, bacteria, and fungi [1]. The number of antibiotic-resistant bacterial strains is increasing all over the world, which potentially may lead to a point when infections would become untreatable with currently available drugs. The routine answer to this problem has been the introduction of new antibiotics that overcome bacterial resistance. In recent years, however, a drop in the research and introduction of new antibiotics has been observed [2-4]. Patients with infections due to antimicrobial-resistant organisms cost the health care system much more than patients infected with antimicrobial-susceptible pathogens [5]. Two species, Gram-positive Staphylococcus aureus and Gram-negative Escherichia coli appeared to be among the most common cause of antibiotic-resistant infections [6].

The light-independent, reviewed in [7], and photodynamic antimicrobial activities of metalloporphyrins [8-10] have attracted interest as potential alternatives to existing antibiotics [11-13]. Non-iron metalloporphyrins have been reported to act as efficient light-independent microbicides against Gram-positive, Gram-negative and mycobacteria, with gallium protoporphyrin IX (GaPPIX) 
being the most efficient $[14,15]$. Protoporphyrin IX-based metalloporphyrins are anionic and enter the cell through the heme-uptake system of bacteria. Consequently, species that do not express heme uptake systems are resistant $[7,14]$. The exact mechanism of metalloporphyrins' light-independent antibacterial action is not known. Supposedly, it is related to inhibition of some essential metabolic pathways, depending on heme-containing enzymes/proteins [7]. On the other hand, the higher sensitivity of catalase- and SOD-deficient mutants, and the fact that anaerobically grown cultures were resistant to non-iron metalloporphyrins, i.e., such compounds are toxic only to actively respiring bacteria [14], suggested that they cause cell damage by either compromising cell respiration or by inducing oxidative stress, or both. Modifications of the peripheral substituents of naturally derived metalloporphyrins dramatically affected their antibacterial activity [14], which stresses the importance of similarity to heme for antibacterial action [7].

A potential advantage of metalloporphyrin-based antibacterials is their low toxicity to eukaryotic cells $[7,14]$. Various porphyrin-based therapeutics, including manganese porphyrin-based SOD mimics, have shown minimal toxicity to laboratory animals and are now in five phase II human clinical trials [16-23]. In our preliminary studies, we found that cationic Mn porphyrins (MnPs) did not show measurable toxicity to human cell cultures and to mice at concentrations tenfold higher than those killing E. coli (unpublished data). While investigating the biological activities of metalloporphyrins, it has been observed that cationic iron ortho $\mathrm{N}$-alkylpyridyl porphyrins (FePs) are much more toxic to E. coli than their manganese analogs [24,25]. Similar findings were observed by Kawakami's group against various cancer cells [26]. The difference in biological activity between cationic Fe and Mn porphyrins are likely related to their differential axial coordination. In contrast to $\mathrm{MnPs}$, which have two weakly axially coordinated water molecules, FePs have one strongly coordinated hydroxo axial ligand, and in the trans-position to it, a weakly bound water molecule [24]. The strong axial binding affects FePs' reactivity in a biological environment as well as pharmacological activities and may in turn induce toxicity to bacteria [24]. The higher toxicity of FePs against E. coli and their good tolerability by mammals $[24,27]$ prompted us to further investigate the bactericidal activity of synthetic FePs.

\section{Materials and Methods}

\subsection{Metalloporphyrins}

The metalloporphyrins used in this study (Figure 1) include Fe(III) $\mathrm{N}$-alkylpyridylporphyrins, whose synthesis and characterization has been described in detail elsewhere [24]. These FePs were specially designed by maintaining the tetrapyrrole core, while modifying the periphery by attaching aliphatic chains of varying length. Consequently, compounds with desired lipophilicity and three-dimensional structure were obtained. The length of the aliphatic chains attached to the pyridyl nitrogen at the meso position varied from ethyl FeTE-2-PyP, Fe(III) meso-tetrakis(N-ethylpyridinium-2-yl)porphyrin), to hexyl FeTnHex-2-PyP, Fe(III) meso-tetrakis(N-hexylpyridinium-2-yl)porphyrin) to octyl FeTnOct-2-PyP, Fe(III) meso-tetrakis (N-octylpyridinium-2-yl)porphyrin). All tested FePs are water-soluble. The charges are omitted throughout the manuscript for clarity. Commercially available gallium protoporphyrin IX (GaPPIX) and hemin were used without further purification. Although isolated as pentachloride salts in solid state, in aqueous systems at physiological $\mathrm{pH}$, cationic FePs coordinate axially with one hydroxo and one water ligands [24], as indicated in Figure 1; for simplicity, axial coordination is omitted throughout the text and in other figures. 


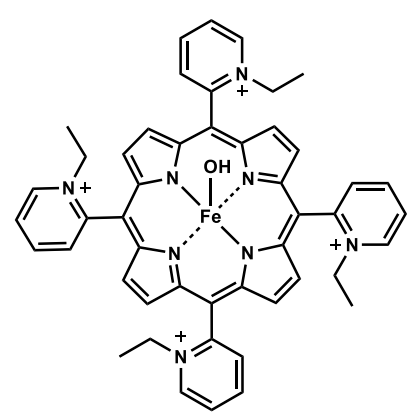

FeTE-2-PyP

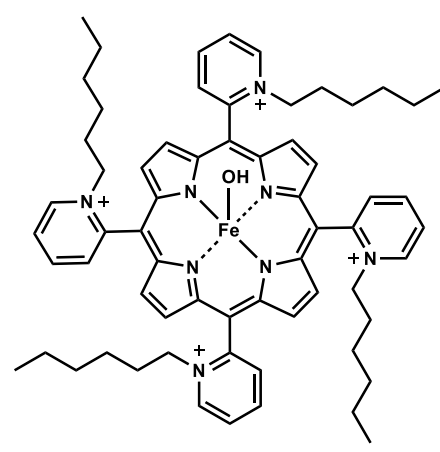

FeTnHex-2-PyP

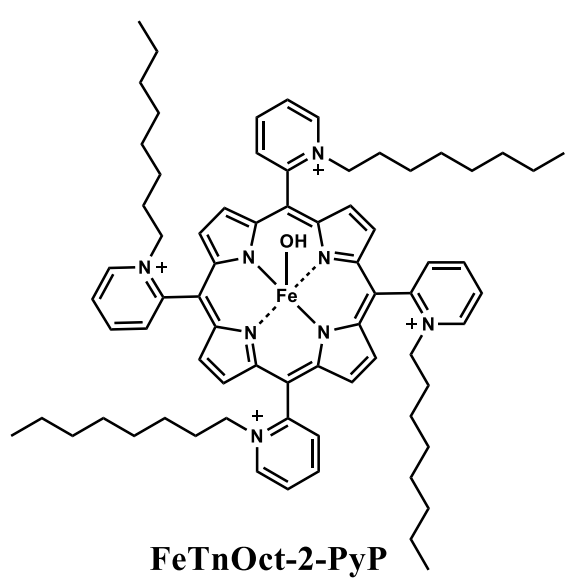

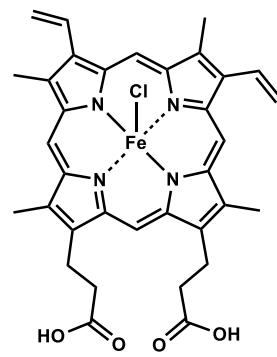

Hemin

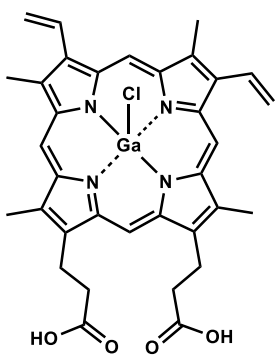

GaPPIX

Figure 1. Structures of metalloporphyrins used in this study. In aqueous medium at $\mathrm{pH} 7.4$, one axial water of Fe(III) ortho N-alkylpyridylporphyrins (FeTE-2-PyP, FeTnHex-2-PyP and FeTnOct-2-PyP) is deprotonated. Consequently, under such conditions cationic iron ortho $\mathrm{N}$-alkylpyridyl porphyrins (FePs) bear one hydroxo $\left(\mathrm{OH}^{-}\right)$ligand and one trans-axially bound water molecule (not shown here for clarity) [24,27]. Hemin and GaPPIX structures are presented in the solid form as they were received.

\subsection{Strains and Growth Conditions}

The Gram-negative strains used to study the antibacterial activity of metalloporphyrins include: antibiotic-sensitive Escherichia coli strain GC4468 (F- $\mathrm{F}^{-}$lac U169 rpsL), QC1799 (same as GC4468 plus $\Delta \operatorname{sodA3}, \Delta \operatorname{sodB}-\mathrm{kan})$ provided by Dr. D. Touati [28]; AB1157 [F- thr-1 leuB6 proA2 his-4 thi-1 argE2 lacY1 galK2 rpsL surE44 ara-14 xyl-15 mtl-1 tsx-33]; KK204 as AB1157 plus fur::kan [29]; MG1655 F' wild-type; LC106, as MG1655 plus $\triangle a h p F:: k a n \Delta(k a t G 17:: \operatorname{Tn} 10) 1 \Delta(k a t E 12:: T n$ 10)1 [30] provided by Dr. J. Imlay, and a clinical E. coli isolate resistant to carbapenems provided by Dr. M. John Albert (Faculty of Medicine, Kuwait University). Gram-positive strains: antibiotic-sensitive Staphylococcus aureus strain ATCC25923 [31], and antibiotic-resistant clinical isolate CC22-SCCmec IV (provided by Dr. E. Udo, Faculty of Medicine, Kuwait University).

Cultures were grown overnight in Luria Bertani (LB) medium with antibiotics added where necessary. For the preparation of LB plates, $15 \mathrm{~g}$ of agar was added to $1 \mathrm{~L}$ of liquid LB medium. Working cultures were grown in M9CA medium (M9 salts, $0.2 \%$ casamino acids, $0.2 \%$ glucose, $3 \mathrm{mg}$ pantothenate, and $5 \mathrm{mg}$ of thiamine per liter) [32]. Growth was monitored by measuring the change of $\mathrm{OD}$ at $600 \mathrm{~nm}$ using a microplate reader [32]. Viability was assessed by dilution of cultures and plating on LB agar plates for counting colonies. To avoid distortion of results due to variations in rate of growth, whenever necessary, cells were washed and resuspended in PBS containing $0.2 \%$ glucose (PBS-glucose).

To avoid light-induced cell damage by metal-free ligands with photosensitizing properties, produced by demetallation of the FePs, cultures and samples were always protected from light. 
To test the contribution of oxygen and reactive species derived from it to FePs bactericidal action, additional experiments were performed in an anaerobic Coy chamber, maintaining oxygen content below the detection limit. All solutions were thoroughly degassed and equilibrated for $30 \mathrm{~min}$ before use.

\subsection{Uptake and Accumulation of FePs in E. coli}

Cellular uptake of FePs was determined as previously described [33]. In brief, mid-log cultures $\left(\mathrm{OD}_{600 \mathrm{~nm}}=0.5-0.7\right)$ grown in M9CA medium were washed and resuspended in PBS-glucose to the same density. FePs were then added to a final concentration of $5 \mu \mathrm{M}$ and cultures were kept on a shaker at $37^{\circ} \mathrm{C}$ for one hour. After the completion of the incubation, cells were rapidly washed with ice-cold PBS, and disrupted by French press. Spectra were recorded and the area under the peak at Soret band was calculated. FeP concentration was determined using a standard curve. Protein concentration was estimated by the method of Lowry [34].

\subsection{Oxygen Consumption by Bacterial Suspensions}

Oxygen consumption was measured as previously described [35] using Biological Oxygen Monitor System (YSI 5300A, YSI Inc., Yellow Springs, OH, USA) equipped with a Clark electrode.

Mid-log E. coli suspensions in PBS-glucose were incubated $60 \mathrm{~min}$ in the dark with FeTnHex-2-PyP at the indicated concentrations. At the end of the incubation period, $3.0 \mathrm{~mL}$ aliquots were transferred to Clark electrode chamber and oxygen consumption was recorded.

\subsection{Data Analysis}

Experiments were repeated at least two times, each sample in triplicate. One-way analysis of variance (ANOVA) was performed using SigmaPlot version 11.0, and $p$ value $<0.05$ was accepted as statistically significant. Data are presented as mean \pm SD.

\section{Results}

\subsection{Effect of FePs on E. coli Proliferation and Viability}

The aim of our initial experiments was to determine how differences in lipophilicity of FePs affect E. coli proliferation. Figure 2 shows that none of the tested FePs prevented E. coli growth at a concentration of $1.0 \mu \mathrm{M}$. At this concentration, FeTE-2-PyP induced $\sim 4 \mathrm{~h}$ lag of proliferation, but did not affect the growth rate. At $3.0 \mu \mathrm{M}$, the most hydrophilic FeP, FeTE-2-PyP, completely prevented cell proliferation, while the amphiphilic hexyl derivative FeTnHex-2-PyP only decreased the rate of growth. No cell proliferation was observed in the presence of $5 \mu \mathrm{M}$ FeTE-2-PyP, FeTnHex-2-PyP or FeTnOct-2-PyP.
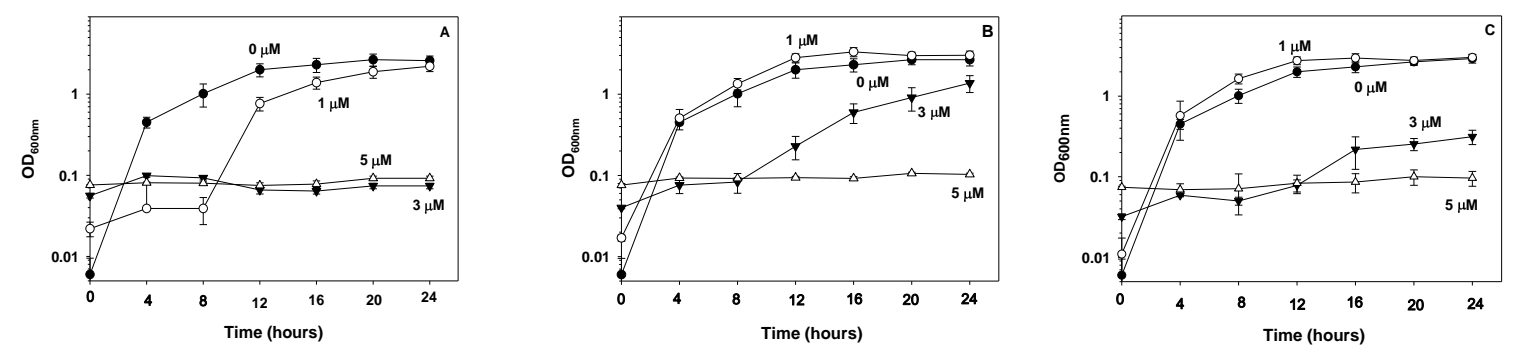

Figure 2. Concentration-dependence of the effect of FePs on E. coli proliferation. Overnight GC4468 LB cultures were diluted 200-fold in M9CA medium. One hundred-microliter aliquots were transferred to a 96-well plate and FePs were added to the specified final concentrations. (A) FeTE-2-PyP; (B) FeTnHex-2-PyP; (C) FeTnOct-2-PyP. Proliferation was monitored by measuring the change of OD at $600 \mathrm{~nm}$ using a microplate reader. Results are presented as mean \pm SD. 
To find out if the effect of the FePs was only bacteriostatic and bacteria remain viable, after completion of the growth experiments $(24 \mathrm{~h})$, the content of the wells where no proliferation was observed ( $5 \mu \mathrm{M}$ FePs), was evenly spread on LB agar plates for counting colonies. Cell number in wells at zero time was used for comparison. The number of viable cells decreased by about four log units when cultures were treated with FeTE-2-PyP. No colonies were observed in wells treated with FeTnHex-2-PyP or FeTnOct-2-PyP (Figure 3). These results show that the amphiphilic hexyl and octyl derivatives exerts much stronger bactericidal action than the hydrophilic ethyl analog.

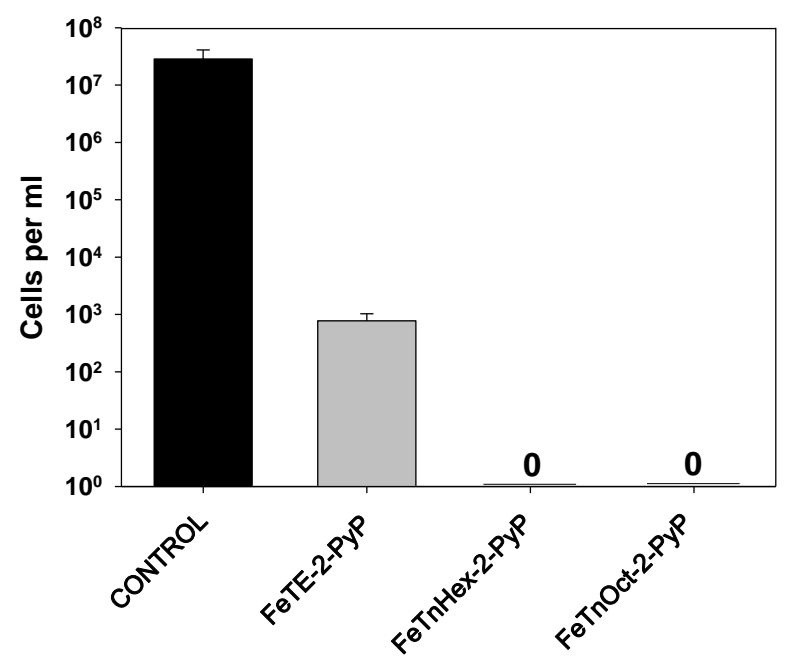

Figure 3. Bactericidal action of FePs. All conditions were as in Figure 2. After $24 \mathrm{~h}$ of monitoring growth, the content of wells with no increase in $\mathrm{OD}_{600 \mathrm{~nm}}$ was evenly spread on agar plates and after $24 \mathrm{~h}$ of incubation at $37^{\circ} \mathrm{C}$, colonies were counted. The plates were left in the incubator for an additional $24 \mathrm{~h}$ and colonies were recounted. Control shows cell number at the beginning of the experiment (zero time). Results are presented as mean $\pm \mathrm{SD}$.

Since FeTnHex-2-PyP demonstrated the lowest toxicity in animal experiments [24], it was selected for further investigations.

The results presented in Figure 3 were obtained after E. coli was exposed to FePs for 24 h. It is not clear what would be the effect if contact with the compound was much shorter. To answer this question, E. coli was grown to mid-log phase $\left(\mathrm{OD}_{600 \mathrm{~nm}}=0.5-0.6\right)$, the cells were thoroughly washed, resuspended in PBS-glucose to avoid cell proliferation during incubation, and treated with $5 \mu \mathrm{M}$ FeTnHex-2-PyP. Figure 4 A shows that short treatment ( $15 \mathrm{~min})$ kills $\sim 40 \%$ of the cells. Exposure for two hours achieved $~ 95 \%$ viability loss, and exposure for four hours killed practically all bacterial cells.

Another variable that might affect FeTnHex-2-PyP bactericidal effect can be the compound to cell number ratio. Experiments demonstrated that at $5 \mu \mathrm{M} \mathrm{FeP}$, maximal bactericidal efficiency could be achieved if cell number did not exceed $\sim 7 \times 10^{8}$ cells $/ \mathrm{mL}$. Five-fold increase in the initial cell number resulted in a $\sim 30 \%$ decrease in FeTnHex-2-PyP bactericidal activity (Figure 4B). 

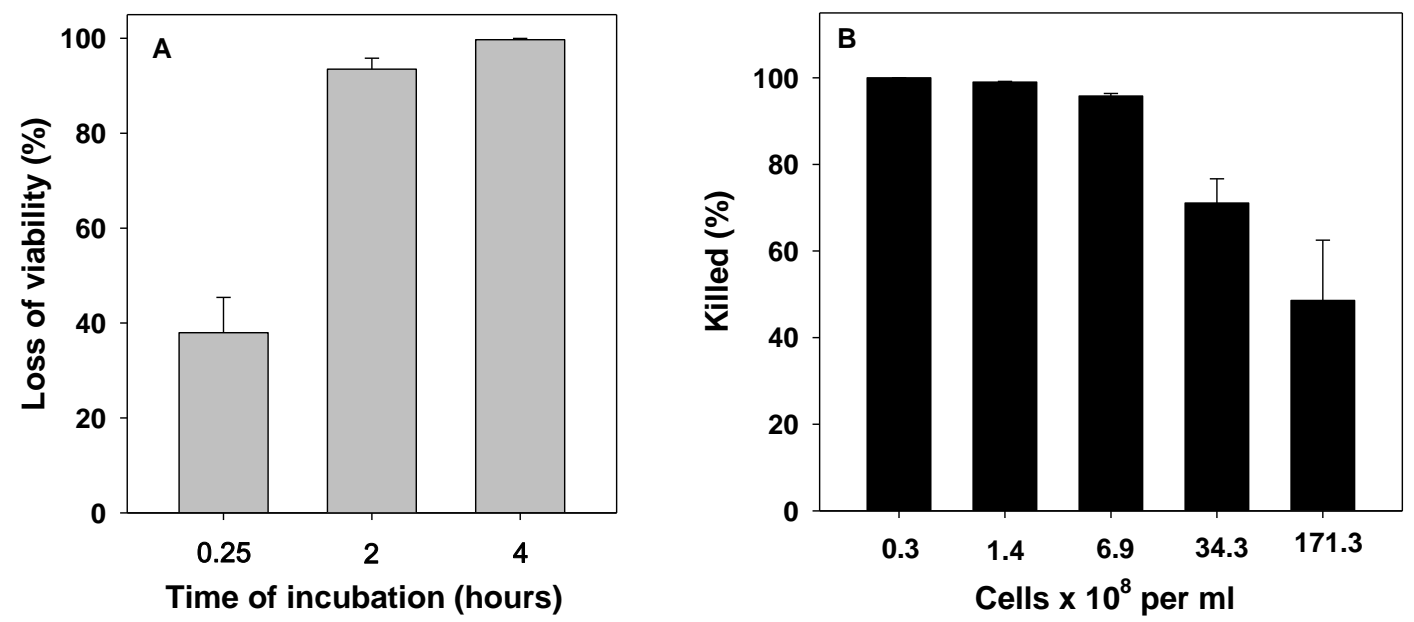

Figure 4. Effect of duration of E. coli exposure to FeTnHex-2-PyP and cell number on cell viability. (A) E. coli suspensions in PBS-glucose $\left(\sim 7 \times 10^{8}\right.$ cells $\left./ \mathrm{mL}\right)$ were incubated with $5 \mu \mathrm{M}$ FeTnHex-2-PyP at $37^{\circ} \mathrm{C}$ and $200 \mathrm{rpm}$. At the indicated times, aliquots were properly diluted and plated for counting colonies. (B) All conditions were as in Panel A except that cell number varied, but time of incubation was fixed to two hours. Results are presented as mean \pm SD.

\subsection{Comparison of FeTnHex-2-PyP with GaPPIX and Hemin}

Previous studies have revealed that hemin [7] and non-iron porphyrins such as Ga-protoporphyrin IX [14] were efficient against certain bacterial species. A comparison under the selected experimental conditions shows (Figure 5) that neither Ga-protoporphyrin IX nor hemin suppressed E. coli proliferation, even when applied at a concentration four-fold higher than that of FeTnHex-2-PyP. This finding is not surprising, because both compounds are negatively charged and our previous studies have demonstrated that only cationic amphiphilic porphyrins easily cross membranes and accumulate to high concentrations in microbial cells $[8,36]$.

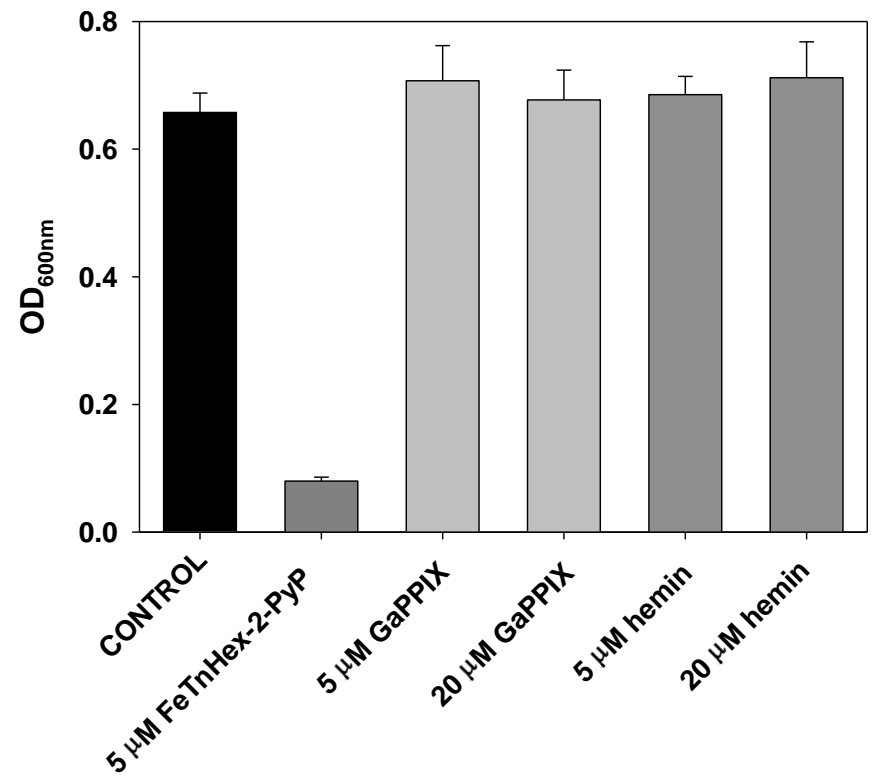

Figure 5. Comparison of the bacteriostatic activity of different types of porphyrins. All conditions were as in Figure 1. Cell density $\left(\mathrm{OD}_{600 \mathrm{~nm}}\right)$ after $24 \mathrm{~h}$ of incubation is shown. Bars represent mean $\pm \mathrm{SD}$ of three separate experiments, each sample run in triplicate. 


\subsection{Cellular Uptake of Fe-Porphyrins}

The data obtained so far suggest that the bactericidal action of FeTnHex-2-PyP depends on the cellular uptake of the compound, leading to suppression of vital biological functions. Incubation of E. coli in the presence of FePs of varying lipophilicity demonstrated that the two amphiphilic FePs, which displayed strong bactericidal activity, accumulated to much higher levels in bacterial cells than the hydrophilic, less active FeTE-2-PyP analog (Figure 6). Based on similar experiments performed with Mn-porphyrin [33] and Zn-porphyrin analogues [8,10], it was established that cationic amphiphilic metalloporphyrins penetrate the cell without the need for a carrier.
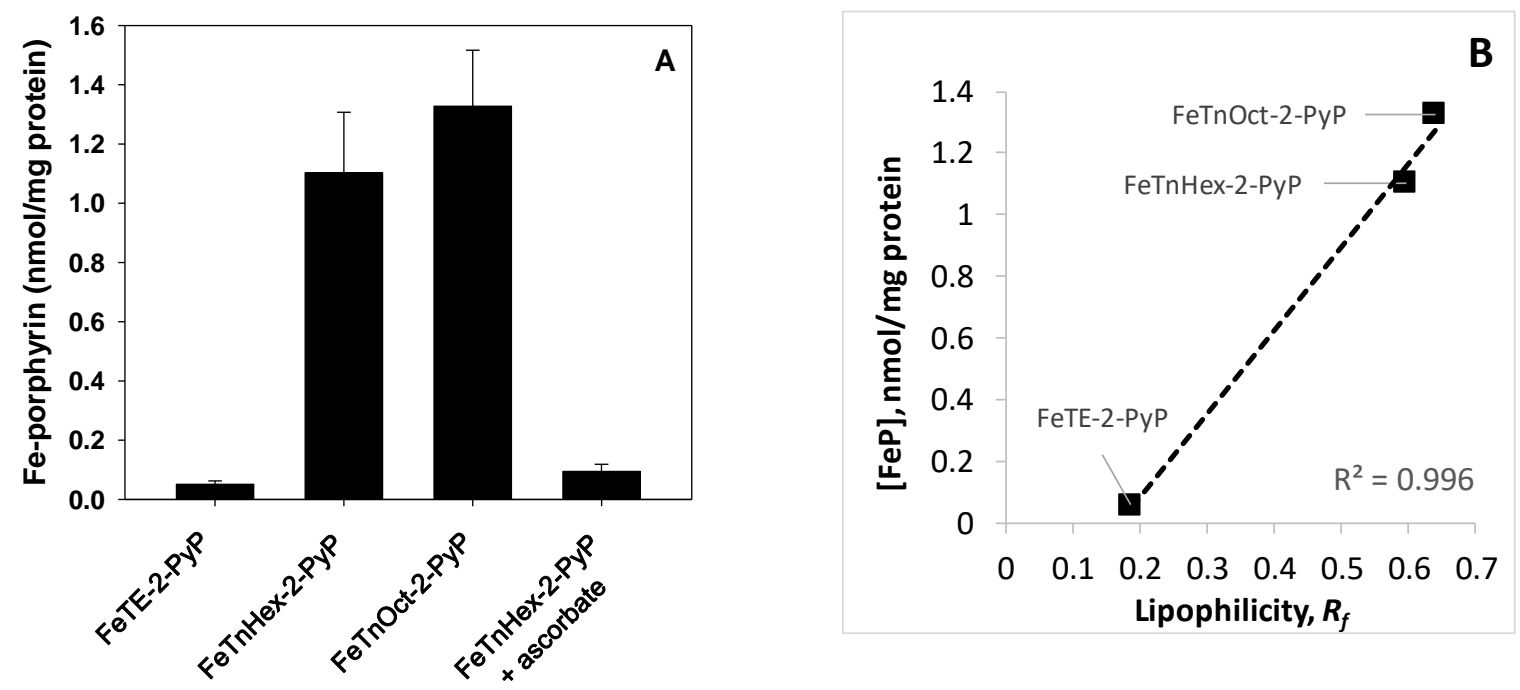

Figure 6. Cellular uptake of FePs. (A) E. coli was treated with FePs alone or in combination with ascorbate. E coli suspensions in PBS-glucose were incubated for one hour with $5 \mu \mathrm{M}$ FePs on a thermostatic shaker at $37^{\circ} \mathrm{C}$ and $200 \mathrm{rpm}$. Where indicated, ascorbate was added to $1.0 \mathrm{mM}$. At the completion of the incubation period, cells were thoroughly washed, resuspended in deionized $\mathrm{H}_{2} \mathrm{O}$ and disrupted by French pressing. Homogenates were cleared from debris by centrifugation and cell-free extracts were used for spectrophotometric assessment of FeP content. The results show mean \pm SD.

(B) Correlation between the lipophilicity (Rf data taken from [24]) and cellular uptake of cationic FePs.

\subsection{Effect of FeTnHex-2-PyP on Oxygen Consumption}

FeTnHex-2-PyP is a redox-active compound and potent SOD mimic [24,25]. Thus, a possible reason for its toxicity may be interference with processes that require transfer of electrons. Among them are various metabolic redox reactions, and cellular respiration. To test if respiration is affected by FePs, oxygen consumption by E. coli treated with FeTnHex-2-PyP was measured. A concentration-dependent suppression of cellular respiration by the $\mathrm{FeP}$ was observed (Figure $7 \mathrm{~A}$ ). Irrespective of the fact that incubation with FeP was reduced to $60 \mathrm{~min}$, loss of viability is inevitable, and suppression of respiration could simply reflect a decreased number of viable cells. To account for the number of viable respiring cells, aliquots taken from the Clark electrode chamber at the time of respiration assay were diluted and plated for counting colonies. When $\mathrm{O}_{2}$ consumption was normalized by the number of viable cells in the chamber, it appeared that the $\mathrm{FeP}$ increased $\mathrm{O}_{2}$ consumption (Figure 7B). The effect was concentration-dependent. One micromole of FeTnHex-2-PyP increased $\mathrm{O}_{2}$ consumption $\sim 2$ fold compared to the non-treated control, $5 \mu \mathrm{M}$ FeTnHex-2-PyP produced about 5-fold increase, and $10 \mu \mathrm{M}$ FeTnHex-2-PyP caused a 10-fold increase in $\mathrm{O}_{2}$ consumption compared to the untreated controls. 

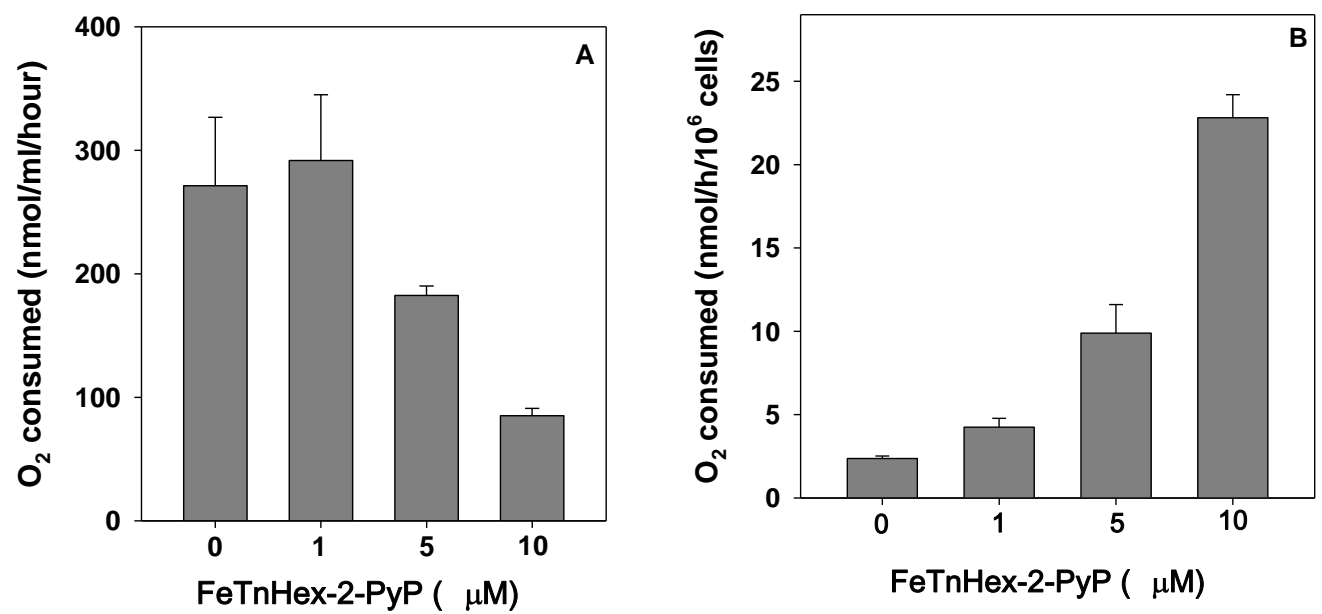

Figure 7. Effect of FeTnHex-2-PyP on $\mathrm{O}_{2}$ consumption by E. coli. E. coli suspensions in PBS-glucose were incubated 60 min with FeTnHex-2-PyP at the indicated concentrations. At the end of the incubation period, $3.0 \mathrm{~mL}$ aliquots were transferred to a thermostatic chamber fitted with a Clark electrode, and oxygen consumption was recorded. After that, cells were suitably diluted and plated on agar LB plates for counting colonies. Results are presented as $\mathrm{nmol} \mathrm{O}_{2}$ consumed per $\mathrm{mL}$ cell suspension (A) or as nmol $\mathrm{O}_{2}$ consumed per $10^{6}$ viable cells (B). Mean $\pm \mathrm{SD}$ of two separate experiments, each sample run in duplicate is presented.

An explanation for the increase in $\mathrm{O}_{2}$ consumption can be found in the reduction of the $\mathrm{Fe}(\mathrm{III}) \mathrm{P}$ by endogenous reductants, among them thiols and ascorbate [37]. Reduced Fe(II)P is rapidly reoxidized, donating an electron to oxygen and generating superoxide anion radicals, whose dismutation results in $\mathrm{H}_{2} \mathrm{O}_{2}$ production [24]. Therefore, the antibacterial activity of $\mathrm{FeP}$ can be attributed to redox-cycling, generating cytotoxic reactive species. This implies that FeP's toxicity should be manifested only aerobically. When the bactericidal activity of $5 \mu \mathrm{M}$ FeTnHex-2-PyP was assessed under anaerobic conditions, however, $99.54 \pm 0.20 \%$ of the cells were killed within $2 \mathrm{~h}$ of incubation.

\subsection{Superoxide Radical, Hydrogen Peroxide, and FeP Decomposition}

If $\mathrm{H}_{2} \mathrm{O}_{2}$ was the main cause for $\mathrm{FeP}^{\prime} \mathrm{s}$ bactericidal effect, then addition of ascorbate would accelerate $\mathrm{FeP}$ redox-cycling and, consequently, FeP toxicity, as was reported before for the Mn-porphyrin analogs [38]. Addition of ascorbate, however, had the opposite effect. One $\mathrm{mM}$ ascorbate added to the cell culture simultaneously with FeTnHex-2-PyP, completely abolished its bactericidal activity. At the same time, ascorbate blocked the uptake of FeTnHex-2-PyP by the cells (Figure 6, far right bar). It appears therefore that redox-cycling and $\mathrm{H}_{2} \mathrm{O}_{2}$ production lead to extracellular $\mathrm{FeP}$ destruction [24] and consequent dismissal of $\mathrm{FeP}$ antibacterial activity. The role of $\mathrm{H}_{2} \mathrm{O}_{2}$ in the mechanism of action of the $\mathrm{FeP}$ was further tested on a catalase/peroxidase-deficient mutant (LC106). The mutant strain appeared to be as sensitive to FeTnHex-2-PyP toxicity as its parent. Thus, aerobically, $5 \mu \mathrm{M}$ FeTnHex-2-PyP killed $88.87 \pm 3.01 \%$ of the parental (MG1655), and $86.98 \pm 4.01 \%$ of the catalase/peroxidase-deficient (LC106) cells. Similar results were obtained when the two strains were incubated with FeTnHex-2-PyP anaerobically; parental $90.33 \pm 3.24 \%$ killed, LC106 $89.48 \pm 4.52 \%$ killed. Neither aerobically nor anaerobically were the differences between the sensitivity of parental and catalase/peroxidase-deficient strains statistically significant. This result was supported by the lack of effect of externally added catalase (1000 units $/ \mathrm{mL}$ ) to E. coli suspensions treated with FeTnHex-2-PyP.

No proof for the contribution of superoxide to the toxic action of FeTnHex-2-PyP was found either. When FeP toxicity to parental and SOD-deficient mutant was compared aerobically, no statistically significant difference was found; parental (GC4468) $89.10 \pm 3.02 \%$ killed, sodA sodB (QC1799) $91.72 \pm 2.26 \%$ killed. 
Reduction of FePs and their reoxidation leads to porphyrin degradation and release of $\mathrm{Fe}^{3+}[24]$, which in the reductive cellular environment is immediately reduced to $\mathrm{Fe}^{2+}$ [39]. Liberation of iron has been proposed as a cause of heme toxicity [40] and might be among the reasons for FeP's bactericidal action. Incubation of bacterial cultures with the iron chelator deferoxamine $(2 \mathrm{mM})$, however, did not protect against FeTnHex-2-PyP bactericidal action $(97.73 \pm 1.26 \%$ of the cells were killed in the absence of deferoxamine and $98.36 \pm 0.6105 \%$ were killed in cultures with deferoxamine).

In many bacterial species, including $E$. coli, iron uptake is controlled by the ferric uptake regulon, fur. It represses the expression of heme uptake systems when there is an abundance of iron, thus preventing iron overload. A fur-deficient mutant (KK204), however, was as sensitive to FeTnHex-2-PyP as its parent was $(96.91 \pm 0.85 \%$ vs. $97.73 \pm 1.52 \%$ killed $)$. This result again shows that FeTnHex-2-PyP toxicity does not depend on bacterial heme uptake system.

\subsection{Bactericidal Action of FeTnHex-2-PyP against S. aureus}

So far all experiments were carried out using a Gram-negative microorganism, E. coli. A Gram-positive species, S. aureus, was reported to be highly susceptible to heme toxicity [40]. By analogy, it could be expected that $S$. aureus would be more sensitive to FeP toxicity than is E. coli. Indeed, in contrast to E. coli, more than $93 \%$ of S. aureus cells were killed at FeTnHex-2-PyP concentrations as low as $1 \mu \mathrm{M}$ (Figure 8).

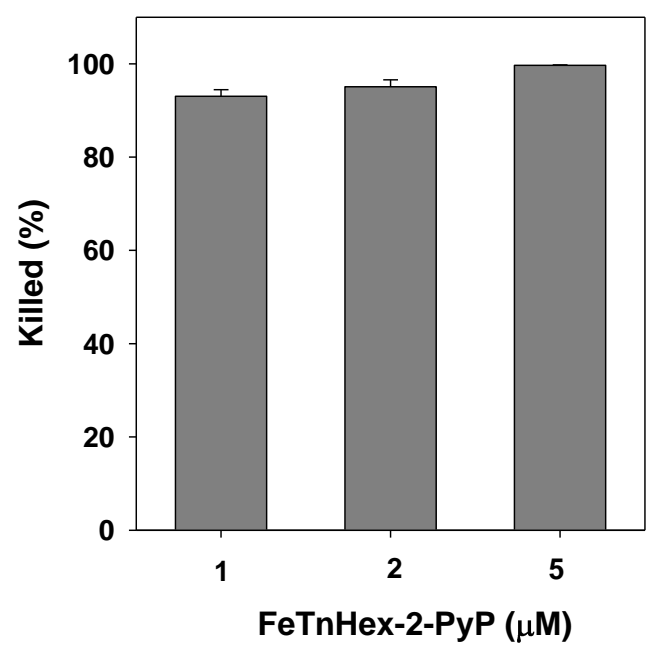

Figure 8. Sensitivity of S. aureus to FeTnHex-2-PyP toxicity. S. aureus (ATCC25923 strain) suspensions in PBS-glucose were incubated two hours with FeTnHex-2-PyP at $37^{\circ} \mathrm{C}$ and $200 \mathrm{rpm}$. At the end of the incubation period, aliquots were properly diluted and plated for counting colonies. Results are presented as mean $\pm \mathrm{SD}$.

\subsection{Resistance to Antibiotics and FeP Bactericidal Effect}

Resistance to antibiotics had no effect on the antibacterial activity of the FeP. An antibiotic-resistant clinical S. aureus isolate CC22-SCCmec IV was as sensitive to killing by $5 \mu \mathrm{M}$ FeTnHex-2-PyP as the antibiotic-sensitive ATCC25923 strain (99.38 $\pm 0.57 \%$ vs. $99.84 \pm 0.75 \%$ killed). Similar results were obtained when a carbapenems-resistant E. coli clinical isolate was tested (antibiotic-sensitive, $95.85 \pm 1.06 \%$ vs. carbapenems-resistant, $97.30 \pm 0.94 \%$ killed).

\section{Discussion}

The results obtained in this study show that ortho cationic Fe(III) $N$-alkylpyridylporphyrins display strong bacteriostatic and bactericidal activities. Bactericidal action depended on FePs lipophilicity, which in turn defines the cellular uptake of the compound. Accumulation of FeP in bacterial cells seems to be crucial for bactericidal action. 
FeTnHex-2-PyP increased oxygen consumption by E. coli suspensions in a concentration-dependent manner. Such an increase can be attributed to redox-cycling of the FeP between reduced $+2\left(\mathrm{Fe}^{\mathrm{II}} \mathrm{P}\right)$ and oxidized $+3\left(\mathrm{Fe}^{\mathrm{III}} \mathrm{P}\right)$ states, while donating an electron to oxygen, converting it to superoxide and, consequently, to hydrogen peroxide; both superoxide and peroxide are bound to the Fe center [24,41] (Scheme 1). Among cellular reductants that can reduce metalloporphyrins, ascorbate and thiols [42-44] are found at millimolar concentrations in most cells. The reactions are analogous to redox-cycling of heme iron [45].

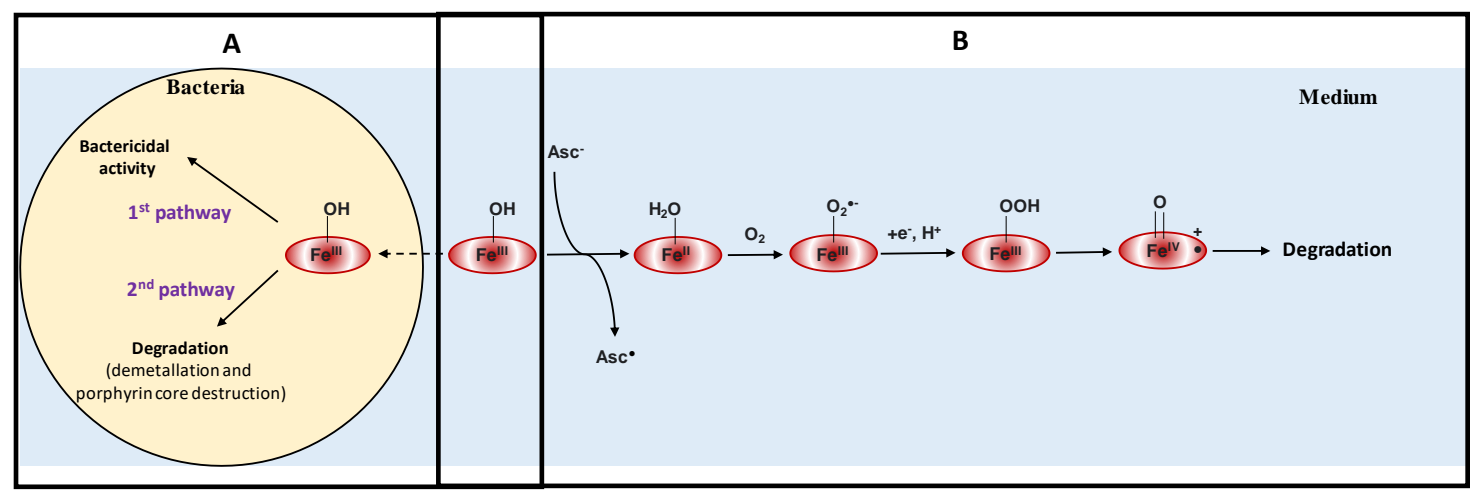

Scheme 1. Proposed intracellular (A) and extracellular (B) conversions of FeTnHex-2-PyP. In cells, FePs can undergo two major pathways. We hypothesized that the 1st pathway results in the bactericidal effect of FeP. FePs have strong preference for axial bonding, particularly nitrogen-containing ligands such as amino groups of proteins, and the bases of DNA and RNA. Such binding may interfere with cellular metabolism and induce bactericidal effect. The 2nd pathway describes the degradation of FePs in the presence of cellular reductants (such as ascorbate, glutathione, cysteine etc.). When ascorbate $\left(\mathrm{Asc}^{-}\right)$acts as an one-electron reductant, its oxidation results in formation of ascorbyl radical (Asc ${ }^{\bullet}$ ), while $\mathrm{Fe}{ }^{\mathrm{III}} \mathrm{P}$ is reduced to $\mathrm{Fe}^{\mathrm{II}} \mathrm{P}$. In a next step, $\mathrm{Fe}^{\mathrm{II}} \mathrm{P}$ binds oxygen and gives rise to $\left.\mathrm{Fe}^{\mathrm{III}} \mathrm{P}_{\left(\mathrm{O}_{2}\right.}{ }^{\bullet-}\right)$ due to intramolecular electron transfer. This species gets reduced with one electron in the presence of proton, $\mathrm{H}^{+}$, to iron hydroperoxo species, $\mathrm{Fe}^{\mathrm{III}} \mathrm{P}-\mathrm{O}-\mathrm{O}-\mathrm{H}$, which in turn undergoes $\mathrm{O}-\mathrm{O}$ homolysis, leading to the solvent caged intermediate $\left[\mathrm{H}_{3} \mathrm{O}^{+}, \mathrm{O}=\mathrm{Fe}^{\mathrm{IV}} \mathrm{P},{ }^{\bullet} \mathrm{OH}\right]$. This step is followed by one electron oxidation of $\mathrm{O}=\mathrm{Fe}^{\mathrm{IV}} \mathrm{P}$ by hydroxyl radical, ${ }^{\bullet} \mathrm{OH}$, to yield the species in which Fe oxidizes its own ligand, $\mathrm{Fe}(\mathrm{IV})$ porphyrin $\pi$ cation radical, $\left[\mathrm{O}=\mathrm{Fe}^{\mathrm{IV}} \mathrm{P}^{\bullet+}\right]$ [46]. Subsequently, this species falls apart into free $\mathrm{Fe}^{3+}$ and oxidized/degraded ligand. The degradation of $\mathrm{O}=\mathrm{Fe}^{\mathrm{IV}} \mathrm{P}^{\bullet+}$ would compete with the substrate oxidation by this species in cellular environment $[24,25,45]$. The pathway is consistent with our data, as no intracellular FeP could be detected in the uptake experiments when FeP was incubated together with ascorbate (Figure 6).

No proof that $\mathrm{O}_{2}{ }^{\bullet-}$ and $\mathrm{H}_{2} \mathrm{O}_{2}$ contributed to FeTnHex-2-PyP toxicity was found. The antibacterial activity of FeTnHex-2-PyP was not prevented by catalase or anaerobiosis and neither $\operatorname{sodA} \operatorname{sod} B$ nor catalase/peroxidase-deficient mutants showed higher sensitivity to the FeP than their corresponding parents. These results, along with literature evidence, imply that these reactive species remain bound to the FeP, causing its rapid decomposition into free iron and degradation products [24,25,47]. Neither free Fe nor reactive species or porphyrin degradation products appeared to be a cause of FePs' bactericidal activity.

FeTnHex-2-PyP was more toxic to a Gram-positive species, S. aureus, than to the Gram-negative E. coli. This implies that structure and permeability of the cell envelope, which determine the cell penetration and accumulation of the FePs, modulate the toxicity of the metalloporphyrin. Resistance to antibiotics did not affect sensitivity to FeTnHex-2-PyP in either of the tested microbial species.

Similar to heme, mechanisms of FePs bacterial toxicity seem to be complex and require detailed investigations. It has been hypothesized [25] that the toxicity of FePs might be due to their high affinity for axial ligation [48]. High cellular protein concentration makes peptides the most likely candidates for binding FeP. By analogy with heme, one can expect that amino acid residues acting as ligands in 
naturally occurring hemoproteins (His, Tyr, Met, Lys, and Cys) [49,50] would also have high affinity towards synthetic Fe-porphyrins. Ligation of FeP to amino acid side chains can eventually disrupt essential protein functions, which could cause cell death. Binding of FePs to proteins could interfere with enzymatic, cell signaling, and other peptide functions, and could lead to the disruption of the plasma membrane barrier and the suppression of metabolic pathways, etc.

\section{Conclusions}

In conclusion, at relatively low concentrations (1-5 $\mu \mathrm{M})$, an amphiphilic FeP exhibited potent antibacterial activity, which depended on the uptake and accumulation of the compound into bacterial cells. Similarly to heme, the tested FeP was more toxic to the Gram-positive S. aureus than to the Gram-negative E. coli. Aerobically, the antibacterial activity of the FeP has been limited by the porphyrin destruction, a consequence of FeP redox cycling. Therefore, the antibacterial activity of the $\mathrm{FeP}$ depends on the intactness of the porphyrin structure and does not result from decomposition products. The lower toxicity of FeTnHex-2-PyP to laboratory animals and its strong bactericidal activity give hope that similar compounds with higher stability might in the future be developed as microbicides against drug-resistant pathogens.

Author Contributions: Conceptualization, L.B., I.B.-H. and A.T.; methodology, L.B.; software, L.B.; validation, L.B., I.B.-H. and A.T.; formal analysis, L.B.; investigation, L.B.; resources, L.B., I.B.-H. and A.T.; data curation, L.B.; writing-original draft preparation, L.B.; writing-review and editing, L.B., I.B.-H. and A.T.; visualization, L.B., I.B.-H. and A.T.; supervision, L.B.; project administration, L.B.; funding acquisition, L.B. and I.B.-H. All authors have read and agreed to the published version of the manuscript.

Funding: This research was funded by Kuwait University, Kuwait, grant number MB01/18.

Acknowledgments: The authors are grateful to F. Sequeira, S. Kaur, and Milini Thomas for excellent technical assistance, and to Jim Imlay (University of Illinois at Urbana-Champaign, Urbana, IL, USA), Danielle Touati (Institute Jacques Monod, CNRS, University Paris, France), M. John Albert (Kuwait University, Kuwait), and E. Udo (Kuwait University, Kuwait) for providing the bacterial strains used herein.

Conflicts of Interest: The authors declare no conflict of interest.

\section{References}

1. WHO. Antimicrobial Resistance: Global Report on Surveillance 2014; WHO Press: Geneva, Switzerlad, 2014; ISBN 9789241564748.

2. Coates, A.R.M.; Hu, Y. Novel approaches to developing new antibiotics for bacterial infections. Br. J. Pharmacol. 2007, 152, 1147-1154. [CrossRef] [PubMed]

3. Spellberg, B.; Guidos, R.; Gilbert, D.; Bradley, J.; Boucher, H.W.; Scheld, W.M.; Bartlett, J.G.; Edwards, J., Jr. The epidemic of antibiotic-resistant infections: A call to action for the medical community from the infectious diseases society of America. Clin. Infect. Dis. 2008, 46, 155-164. [CrossRef] [PubMed]

4. Tillotson, G.S. Antibiotic development: A victim of market forces? IDrugs 2008, 11, 340-345. [PubMed]

5. Maragakis, L.L.; Perencevich, E.N.; Cosgrove, S.E. Clinical and economic burden of antimicrobial resistance. Expert Rev. Anti-Infect. Ther. 2008, 6, 751-763. [CrossRef] [PubMed]

6. Jones, R.N. Resistance patterns among nosocomial pathogens: Trends over the past few years. Chest 2001, 119, 397S-404S. [CrossRef] [PubMed]

7. Stojiljkovic, I.; Evavold, B.D.; Kumar, V. Antimicrobial properties of porphyrins. Expert Opin. Investig. Drugs 2001, 10, 309-320. [CrossRef]

8. Thomas, M.; Craik, J.D.; Tovmasyan, A.; Batinic-Haberle, I.; Benov, L.T. Amphiphilic cationic Zn-porphyrins with high photodynamic antimicrobial activity. Future Microbiol. 2015, 10, 709-724. [CrossRef]

9. Awad, M.M.; Tovmasyan, A.; Craik, J.D.; Batinic-Haberle, I.; Benov, L.T. Important cellular targets for antimicrobial photodynamic therapy. Appl. Microbiol. Biot. 2016, 100, 7679-7688. [CrossRef]

10. Alenezi, K.; Tovmasyan, A.; Batinic-Haberle, I.; Benov, L.T. Optimizing Zn porphyrin-based photosensitizers for efficient antibacterial photodynamic therapy. Photodiagn. Photodyn. Ther. 2017, 17, 154-159. [CrossRef]

11. Hamblin, M.R. Antimicrobial photodynamic inactivation: A bright new technique to kill resistant microbes. Curr. Opin. Microbiol. 2016, 33, 67-73. [CrossRef] 
12. Kashef, N.; Huang, Y.Y.; Hamblin, M.R. Advances in antimicrobial photodynamic inactivation at the nanoscale. Nanophotonics 2017, 6, 853-879. [CrossRef] [PubMed]

13. Wainwright, M.; Maisch, T.; Nonell, S.; Plaetzer, K.; Almeida, A.; Tegos, G.P.; Hamblin, M.R. Photoantimicrobials-Are we afraid of the light? Lancet Infect. Dis. 2017, 17, e49-e55. [CrossRef]

14. Stojiljkovic, I.; Kumar, V.; Srinivasan, N. Non-iron metalloporphyrins: Potent antibacterial compounds that exploit haem/Hb uptake systems of pathogenic bacteria. Mol. Microbiol. 1999, 31, 429-442. [CrossRef] [PubMed]

15. Bozja, J.; Yi, K.; Shafer, W.M.; Stojiljkovic, I. Porphyrin-based compounds exert antibacterial action against the sexually transmitted pathogens Neisseria gonorrhoeae and Haemophilus ducreyi. Int. J. Antimicrob. Agents 2004, 24, 578-584. [CrossRef]

16. Ni, Y. Metalloporphyrins and functional analogues as MRI contrast agents. Curr. Med. Imaging Rev. 2008, 4, 96-112. [CrossRef]

17. Crow, J.P. Catalytic antioxidants to treat amyotropic lateral sclerosis. Expert Opin. Investig. Drugs 2006, 15, 1383-1393. [CrossRef]

18. Orrell, R.W. AEOL-10150 Aeolus. Curr. Opin. Investig. Drugs 2006, 7, 70-80.

19. Kinnula, V.L. Production and degradation of oxygen metabolites during inflammatory states in the human lung. Curr. Drug Targets Inflamm. Allergy 2005, 4, 465-470. [CrossRef]

20. Dennery, P.A. Metalloporphyrins for the treatment of neonatal jaundice. Curr. Opin. Pediatrics 2005, 17, 167-169. [CrossRef]

21. Batinic-Haberle, I.; Spasojevic, I. 25 years of development of Mn porphyrins-from mimics of superoxide dismutase enzymes to thiol signaling to clinical trials: The story of our life in the USA. J. Porphyr. Phthalocyanines 2019, 23, 1326-1335. [CrossRef]

22. Peters, K.; Kirkpatrick, J.; Batinic-Haberle, I.; Affronti, M.; Woodring, S.; Iden, D.; Panta, S.; Lipp, E.; Healy, P.; Herndon, J.; et al. ACTR-28. PHASE 1 Dose Escalation Trial Of The Safety Of Bmx-001 Concurrent With Radiation Therapy And Temozolomide In Newly Diagnosed Patients With High-Grade Gliomas. Neuro-Oncology 2018, 20, vi17. [CrossRef]

23. Peters, K.B.; Kirkpatrick, J.P.; Batinic-Haberle, I.; Affronti, M.L.; Woodring, S.; Iden, D.; Lipp, E.S.; Boyd, K.; Healy, P.; Herndon, J.; et al. First in Human Clinical Trial of a Metalloporphyrin Dual Radioprotectant and Radiosensitizer, BMX-001, in Newly Diagnosed High-Grade Glioma Undergoing Concurrent Chemoradiation. Int. J. Radiat. Oncol. Biol. Phys. 2019, 105, E106. [CrossRef]

24. Tovmasyan, A.; Weitner, T.; Sheng, H.X.; Lu, M.M.; Rajic, Z.; Warner, D.S.; Spasojevic, I.; Reboucas, J.S.; Benov, L.; Batinic-Haberle, I. Differential Coordination Demands in Fe versus Mn Water-Soluble Cationic Metalloporphyrins Translate into Remarkably Different Aqueous Redox Chemistry and Biology. Inorg. Chem. 2013, 52, 5677-5691. [CrossRef]

25. Batinić-Haberle, I.; Spasojević, I.; Hambright, P.; Benov, L.; Cmmbliss, A.L.; Fridovich, I. Relationship among redox potentials, proton dissociation constants of pyrrolic nitrogens, and in vivo and in vitro superoxide dismutating activities of manganese(III) and iron(III) water-soluble porphyrins. Inorg. Chem. 1999, 38, 4011-4022. [CrossRef]

26. Ohse, T.; Nagaoka, S.; Arakawa, Y.; Kawakami, H.; Nakamura, K. Cell death by reactive oxygen species generated from water-soluble cationic metalloporphyrins as superoxide dismutase mimics. J. Inorg. Biochem. 2001, 85, 201-208. [CrossRef]

27. Li, L.; Tovmasyan, A.; Sheng, H.; Xu, B.; Sampaio, R.S.; Reboucas, J.S.; Warner, D.S.; Batinic-Haberle, I.; Spasojevic, I. Fe Porphyrin-Based SOD Mimic and Redox-Active Compound, (OH)FeTnHex-2-PyP ${ }^{4+}$, in a Rodent Ischemic Stroke (MCAO) Model: Efficacy and Pharmacokinetics as Compared to Its Mn Analogue, $\left(\mathrm{H}_{2} \mathrm{O}\right) \mathrm{MnTnHex}-2-\mathrm{PyP}^{5+}$. Antioxidants 2020, 9, 467. [CrossRef] [PubMed]

28. Liochev, S.I.; Benov, L.; Touati, D.; Fridovich, I. Induction of the soxRS regulon of Escherichia coli by superoxide. J. Biol. Chem. 1999, 274, 9479-9481. [CrossRef]

29. Varghese, S.; Wu, A.; Park, S.; Imlay, K.R.C.; Imlay, J.A. Submicromolar hydrogen peroxide disrupts the ability of fur protein to control free-iron levels in Escherichia coli. Mol. Microbiol. 2007, 64, 822-830. [CrossRef] 
30. Seaver, L.C.; Imlay, J.A. Are respiratory enzymes the primary sources of intracellular hydrogen peroxide? J. Biol. Chem. 2004, 279, 48742-48750. [CrossRef]

31. Udo, E.E.; Jacob, L.E.; Mathew, B. A cadmium resistance plasmid, pXU5, in Staphylococcus aureus, strain ATCC25923. FEMS Microbiol. Lett. 2000, 189, 79-80. [CrossRef]

32. Tovmasyan, A.; Reboucas, J.S.; Benov, L. Simple biological systems for assessing the activity of superoxide dismutase mimics. Antioxid. Redox Signal. 2014, 20, 2416-2436. [CrossRef] [PubMed]

33. Kos, I.; Benov, L.; Spasojević, I.; Rebouças, J.S.; Batinić-Haberle, I. High lipophilicity of meta Mn(III) $\mathrm{N}$-alkylpyridylporphyrin-based superoxide dismutase mimics compensates for their lower antioxidant potency and makes them as effective as ortho analogues in protecting superoxide dismutase-deficient Escherichia coli. J. Med. Chem. 2009, 52, 7868-7872. [CrossRef] [PubMed]

34. Lowry, O.H.; Rosebrough, N.J.; Farr, A.L.; Randall, R.J. Protein measurement with the Folin phenol reagent. J. Biol. Chem. 1951, 193, 265-275. [PubMed]

35. Benov, L. Effect of growth media on the MTT colorimetric assay in bacteria. PLoS ONE 2019, 14, e0219713. [CrossRef] [PubMed]

36. Moghnie, S.; Tovmasyan, A.; Craik, J.; Batinic-Haberle, I.; Benov, L. Cationic amphiphilic Zn-porphyrin with high antifungal photodynamic potency. Photochem. Photobiol. Sci. 2017, 16, 1709-1716. [CrossRef]

37. Tovmasyan, A.G.; Rajic, Z.; Spasojevic, I.; Reboucas, J.S.; Chen, X.; Salvemini, D.; Sheng, H.; Warner, D.S.; Benov, L.; Batinic-Haberle, I. Methoxy-derivatization of alkyl chains increases the in vivo efficacy of cationic Mn porphyrins. Synthesis, characterization, SOD-like activity, and SOD-deficient E. coli study of meta Mn(iii) N-methoxyalkylpyridylporphyrins. Dalton Trans. 2011, 40, 4111-4121. [CrossRef]

38. Batinić-Haberle, I.; Rajić, Z.; Benov, L. A combination of two antioxidants (an SOD mimic and ascorbate) produces a pro-oxidative effect Forcing Escherichia coli to adapt via induction of oxyR regulon. Anti-Cancer Agents Med. Chem. 2011, 11, 329-340.

39. Liochev, S.I. The role of iron-sulfur clusters in in vivo hydroxyl radical production. Free Radic. Res. 1996, 25, 369-384. [CrossRef]

40. Anzaldi, L.L.; Skaar, E.P. Overcoming the Heme Paradox: Heme Toxicity and Tolerance in Bacterial Pathogens. Infect. Immun. 2010, 78, 4977-4989. [CrossRef]

41. Atamna, H.; Ginsburg, H. Heme degradation in the presence of glutathione. A proposed mechanism to account for the high levels of non-heme iron found in the membranes of hemoglobinopathic red blood cells. J. Biol. Chem. 1995, 270, 24876-24883. [CrossRef]

42. Tovmasyan, A.; Maia, C.G.C.; Weitner, T.; Carballal, S.; Sampaio, R.S.; Lieb, D.; Ghazaryan, R.; Ivanovic-Burmazovic, I.; Ferrer-Sueta, G.; Radi, R.; et al. A comprehensive evaluation of catalase-like activity of different classes of redox-active therapeutics. Free Radic. Biol. Med. 2015, 86, 308-321. [CrossRef] [PubMed]

43. Tovmasyan, A.; Bueno-Janice, J.C.; Jaramillo, M.C.; Sampaio, R.S.; Reboucas, J.S.; Kyui, N.; Benov, L.; Deng, B.; Huang, T.T.; Tome, M.E.; et al. Radiation-Mediated Tumor Growth Inhibition Is Significantly Enhanced with Redox-Active Compounds That Cycle with Ascorbate. Antioxid. Redox Signal. 2018, 29, 1196-1214. [CrossRef] [PubMed]

44. Batinic-Haberle, I.; Tome, M.E. Thiol regulation by Mn porphyrins, commonly known as SOD mimics. Redox Biol. 2019, 25, 101139. [CrossRef] [PubMed]

45. Nagababu, E.; Rifkind, J.M. Heme degradation by reactive oxygen species. Antioxid. Redox Signal. 2004, 6, 967-978.

46. Han, A.R.; Jin Jeong, Y.; Kang, Y.; Yoon Lee, J.; Sook Seo, M.; Nam, W. Direct evidence for an iron(IV)-oxo porphyrin $\pi$-cation radical as an active oxidant in catalytic oxygenation reactions. Chem. Commun. 2008, 1076-1078. [CrossRef]

47. Spasojevic, I.; Colvin, O.M.; Warshany, K.R.; Batinic-Haberle, I. New approach to the activation of anti-cancer pro-drugs by metalloporphyrin-based cytochrome $\mathrm{P} 450$ mimics in all-aqueous biologically relevant system. J. Inorg. Biochem. 2006, 100, 1897-1902. [CrossRef]

48. Scheidt, W.R.; Reed, C.A. Spin-State/Stereochemical Relationships in Iron Porphyrins: Implications for the Hemoproteins. Chem. Rev. 1981, 81, 543-555. [CrossRef] 
49. McIntosh, J.A.; Heel, T.; Buller, A.R.; Chio, L.; Arnold, F.H. Structural Adaptability Facilitates Histidine Heme Ligation in a Cytochrome P450. J. Am. Chem. Soc. 2015, 137, 13861-13865. [CrossRef]

50. Li, T.; Bonkovsky, H.L.; Guo, J.T. Structural analysis of heme proteins: Implications for design and prediction. BMC Struct. Biol. 2011, 11, 13. [CrossRef]

(C) 2020 by the authors. Licensee MDPI, Basel, Switzerland. This article is an open access article distributed under the terms and conditions of the Creative Commons Attribution (CC BY) license (http://creativecommons.org/licenses/by/4.0/). 